\title{
Newborn Country, USA
}

\section{Richard Molteni, MD}

Landing a manned vehicle on the surface of the moon; fingertip access from home through the information highway to any information bit available in the world; eradicating smallpox from the world's population. Regionalizing all of perinatal care in the United States and establishing accountability for the quality of care and the education of maternal/child providers. Developing an understanding and appreciation for the importance of these concepts at a state and national level if neonatal and infant mortality were to be lowered. What could each of these concepts have in common? Each represents extraordinary vision to see a broad view of a challenge; each concept was initially rejected as too enormous an undertaking by the experts of the day. Most importantly, each demanded a fierce commitment to a dream that would raise the bar for a field of human endeavor well beyond that assumed possible by the average individual but which, if successful, would profoundly affect the lives on countless individuals. "Newborn Country, USA" was not an advertising or marketing gimmick to improve market share. Rather it was a very visible model of maternal/child care delivery that established responsibility for outcomes and assured the education of all providers who chose to participate. It was this concept of responsibility that was important-it was no longer each provider's "right" to practice maternal/child health in an unsupervised environment. Outcomes were tracked, providers educated, and families and insurers provided expectations for quality and standards of care. The system did not pit competitors against each other. There were not "dominant" players. This new system was designed to accommodate providers at every level, validate their importance, and collaborate and integrate them into a total system of care. The system was built on interdependence and not hierarchical control. Each performed its appropriate and comfortable level of care in an environment of trust, which permitted a continual process of self-appraisal without fear of retribution. It was the first truly "continuous quality improvement" program in pediatric medicine that never concentrated on the "bad apple" but rather sought to constantly innovate and redesign the system of care delivery for mothers and newborns.

The system Joe Butterfield created, in many ways adapted and expanded from the Belton Myers program in Phoenix, was unique

Children's Hospital and Regional Medical Center, Seattle, WA.

Address correspondence and reprint requests to Richard Molteni, MD, Children's Hospital and Regional Medical Center, 488 Sand Point Way NE, Seattle, WA 98105-0371. in one other very important way. While most other pediatric and neonatal programs were concentrating on the technologic alteration of premature nurseries to neonatal intensive care units, Joe sought a "root cause" approach to the problem of newborn disease. The major risks and pitfalls facing the newborn were primarily related to obstetric management or its complications. It was in this arena that major improvements in neonatal mortality and morbidity would be found. This was a unique concept in the early 1970s, a time when obstetricians were often viewed as the villains in this morality play. There was a widespread pediatric undercurrent that almost implied an actively organized conspiracy to produce injured newborns. Today the concept of noncooperation, presumed or real, is quite impossible to imagine. That atmosphere was present when Joe created a regionalization concept that not only considered obstetric management in the model but also welcomed them openly as equal and essential players. This concept fit comfortably into the "Perinatal Program" at the University of Colorado in which Fred Battaglia and Ed Makowski had created that same essential synergy between neonatal and obstetric medicine in the fetal/maternal/neonatal research arena. The early inclusion of obstetrics in this regional concept assured success and major gains in mortality and morbidity. Again a program founded on respect and cooperation replaced one of finger pointing and specialty dominance.

Joe has always been a great salesman and marketer. His ability to attract attention to a concept or a program with just the right phrase or word is legendary. Of the many buttons with phrases Joe created, my favorite was short, succinct, and to the point: "Home deliveries are for pizzas." This button, which Joe passed out freely, demonstrated another very important part of his personality. Though he continues to be the master politician he has never traded short-term political gain for a decision to look the other way when mothers or newborns are being ignored or injured. Those issues he took on directly and mustered strong political support to correct a clear problem in our delivery system. The solution was not to attack an individual or a group - the answer lay in the correcting process or system.

Joe's success clearly was related to the enormity of his contacts: information lines, strong legislators and medical leaders. Armed with these well-developed support systems he never stepped away from an important concept or standard of care in a community, a state, or the nation. Joe worked in every medical, legislative, and political arena to assure that these messages were clearly heard and that important and powerful politician, business, and medical leaders heard that message and responded to it. He was irascible in his dogged tenacity. Phones were always ringing, letters prolifically written, surprise visits common. Today the fax machine has further intensified Joe's communi- 
cations and e-mail broadened his reach. The issues, however, have never changed - improving health of mothers and children. In this effort he maintained a strong alliance with organizations with similar interests: the American College of Obstetricians and Gynecologists (ACOG), the March of Dimes, the Maternal Child Health Bureau, State Health Departments, the American Academy of Pediatrics (AAP), and especially the Section on Perinatal Pediatrics. He fostered contacts, liaisons, meetings, combined documents, statements, and guidelines. Cooperation and agreement, not competition, always dominated the agenda.

Cross-fertilization, both within the same specialty and across geographics and across all the disciplines dedicated to maternal child health, also characterized Joe's involvement with the AAP. He took the AAP's Chapter and District concept and applied it to perinatal-neonatal medicine as well. He created the District VIII Perinatal Association, the regional embodiment of the Section. State organizations grew or were incorporated into State Chapter Fetus and Newborn Committees. The growth of the Section, its leadership, membership, and influence, had much to do with Joe's guidance and work behind the scenes. All of us who have had the honor of working for the Section at a national level have been all too aware of the extraordinary contributions Joe has made throughout the Section's history. He has been the glue that has held us together, provided the vision, and operationalized our work through his constant attention to detail and tradition. The Perinatal History project, a recent passion of Joe's, is merely a blip in a long list of contributions. The projects are always at a scope that none of the rest of us would consider tackling. A stamp in honor of Virginia Apgar: What better example of this style and perseverance? Those of us who have had the honor to participate throughout the birth and astounding growth of this specialty have watched the giants roam the earth and create a remarkable system of maternal/child and neonatal care. The trip has been rapid and fascinating. Many of those giants

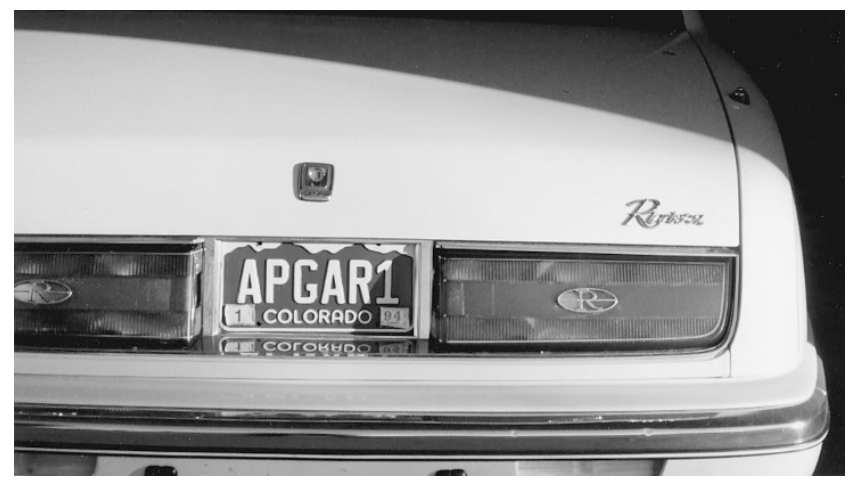

1994: APGAR1, Dr. Butterfield's license plate, a gift of his late daughter, Brigid, just before her death in 1981.

have become Apgar awardees. No finer recognition of Joe's contributions was possible. Though only one of many such honors, the Apgar award personifies all those characteristics Joe holds dear. He lives with the immortals of neonatal medicine. Yet it is the constant vigor and innovation of his thinking throughout those years which sets him apart. An era or decade, an idea, or a concept has never limited him. He constantly adapts dreams, creates, demonstrates, and sells. He is an ever-changing model for those of us who seek to make just one small change in the health of mothers and children. We marvel at his intellect, are amazed by his energy, surprised by the depth of his contacts, and shocked by the speed of his successes. This honor is long overdue. Fortunately this oracle of neonatal/perinatal medicine will continue to guide us into a new millennium of maternal/child health and help us to face the challenges that are yet to be defined. We salute Joe for his perseverance, his vision, and his friendship. May we acquire for ourselves only a few of these qualities. May the discipline retain them all through the development of a new generation of visionaries who learn from the legacy Joe will leave behind. 